\title{
AS CARACTERÍSTICAS DAS PUBLICAÇÕES BRASILEIRAS SOBRE AS IFRS E OS PRONUNCIAMENTOS CONTÁBEIS EM PERIÓDICOS DE ELEVADO IMPACTO
}

\author{
THE FEATURES OF BRAZILIAN PUBLICATIONS ON IFRS AND \\ PRONOUNCEMENTS ACCOUNTING IN PERIODIC OF HIGH IMPACT
}

\author{
Andrea Carla Bordignon Lunedo ${ }^{1}$, Silvana Dalmutt Kruger ${ }^{2}$, \\ Sady Mazzioni ${ }^{3}$, Rogério Lunedo ${ }^{4}$ e Everton Paulo Folletto ${ }^{5}$
}

Recebido em: 15/07/2014 Aprovado em: 11/09/2014

\section{RESUMO}

As discussões acerca do processo de convergência das normas internacionais de contabilidade constituem argumentos motivadores para o desenvolvimento de pesquisas acadêmicas recentes. Tendo isso em vista, este estudo tem por objetivo identificar as principais características das publicações contábeis brasileiras nos periódicos com extrato Qualis Capes A1, A2 e B1, relacionadas às International Financial Reporting Standards (IFRS) e aos pronunciamentos contábeis, no período de 2008 a 2013. Metodologicamente, a pesquisa caracteriza-se como documental e considerou duas bases científicas para a coleta das publicações. A amostra final analisada é composta por 43 artigos, publicados em 10 dos 176 periódicos pesquisados. Os resultados do estudo, por meio da análise de redes, evidenciaram que as principais discussões que permeiam as publicações brasileiras em contabilidade relacionadas às normas internacionais e aos pronunciamentos contábeis nos periódicos nacionais de impacto mais elevado referem-se aos "efeitos e impactos da adoção dos padrões IFRS", representando $60,47 \%$ das pesquisas realizadas. De modo geral, os resultados indicam a baixa inclusão de publicações brasileiras sobre IFRS e pronunciamentos contábeis em periódicos de elevado impacto.

Palavras-chave: Normas internacionais; Pronunciamentos contábeis; IFRS; CPC.

\begin{abstract}
The discussions on the process convergence of international accounting standards are arguments motivators for the development of recent academic research. To contribute to the context, the study aims to identify the main characteristics of Brazilian accounting publications in journals with extract Qualis Capes A1, A2 and B1, related to IFRS and accounting pronouncements, in the period 2008-2013. Methodologically, the research characterized as documentary and found two scientific bases for the collection of publications. The final sample analyzed consists of 43 articles published in 10 journals of the 176 surveyed. The results of the study, through the analysis of networks, showed that the main discussions that permeate Brazilian publications in accounting, related to international standards and pronouncements accounting in national journals of higher impact, refer to "effects and impacts of the adoption of IFRS standards", representing $60.47 \%$ of searches made. Overall, the results indicate for the low inclusion of Brazilian publications on IFRS and accounting pronouncements in journals with high impact and show the characteristics of published studies.
\end{abstract}

Keywords: International standards; Accounting pronouncements; IFRS; CPC.

\footnotetext{
${ }^{1}$ Especialista em Contabilidade e Controladoria pela Universidade Comunitária da Região de Chapecó (Unochapecó), Brasil. E-mail: andreacb@unochapeco.edu.br.

${ }^{2}$ Doutoranda em Contabilidade pela Universidade Federal de Santa Catarina (UFSC). Professora da Universidade Comunitária da Região de Chapecó (Unochapecó), Brasil. E-mail: silvanak@unochapeco.edu.br.

${ }^{3}$ Doutorando em Ciências Contábeis e Administração pela Universidade Regional de Blumenau (FURB). Professor da Universidade Comunitária da Região de Chapecó (Unochapecó), Brasil. E-mail: sady@unochapeco.edu.br.

${ }^{4}$ Especialista em Auditoria e Perícia pela Universidade Comunitária da Região de Chapecó (Unochapecó), Brasil. E-mail: lunedo@unochapeco.edu.br. ${ }^{5}$ Graduando em Ciências Contábeis pela Universidade Comunitária da Região de Chapecó (Unochapecó), Brasil. E-mail: evertonfolletto@unochapeco
} edu.br. 


\section{Introdução}

O processo de internacionalização e padronização das normas de contabilidade - as International Financial Reporting Standards (IFRS), visa possibilitar a comparação das informações contábeis e tornar comum aos distintos países a forma de mensuração, avaliação e evidenciação das informações contábeis. Mais de 130 países estão em fase de convergência para a adoção e implantação das IFRS, com o intuito de garantir a padronização da linguagem contábil mundial (IUDÍCIBUS et al., 2013).

De acordo com Carvalho, Lemes e Costa (2006, p. 15), "A contabilidade internacional surgiu para minorar as agruras de quem quer investir fora de seu país e até hoje tinha que manusear balanços em dezenas de normas contábeis distintas, tentando compatibilizá -las para comparar".

Padoveze, Benedicto e Leite (2012) destacam que as diferenças entre os resultados das demonstrações das companhias publicadas com base nos padrões contábeis do Brasil e dos Estados Unidos, por exemplo, são significativas, exigindo das empresas explicações aos investidores e diversos procedimentos para a realização de auditorias. Nesse contexto, a inserção das IFRS visa minimizar os impactos de procedimentos contábeis distintos entre as diversas economias mundiais, contribuindo para a análise e interpretação das demonstrações contábeis.

Existem significativos desafios a serem enfrentados pelos profissionais envolvidos na adoção das IFRS, tanto na elaboração quanto na compreensão das demonstrações financeiras, considerando que a sua fundamentação é justificada por princípios e não por regras (ERNEST; YOUNG; FIPECAFI, 2010).

Especificamente no cenário contábil brasileiro, o Conselho Federal de Contabilidade (CFC), por meio da Resolução n. ${ }^{\circ} 1.055$, criou o Comitê de Pronunciamentos Contábeis (CPC). A pu- blicação dos pronunciamentos técnicos pelo CFC tem por finalidade harmonizar as normas contábeis brasileiras com as IFRS. Atualmente, estão em vigor 46 pronunciamentos técnicos, 18 interpretações e seis orientações técnicas, provocando inúmeras alterações na mensuração, contabilização e escrituração das demonstrações financeiras (CFC, 2014).

A partir do contexto das alterações advindas do processo de convergência às IFRS, o presente estudo pondera as recomendações de Hopwood (2007), o qual já indicava as principais áreas promissoras dos estudos em contabilidade, salientando que haveria uma tendência de pesquisas voltadas à análise e à forma de padronização das informações contábeis.

Nesse sentido, os estudos de Cardoso et al. (2005) e posteriormente de Macedo, Casa Nova e Almeida (2009) destacam a importância de mapear e identificar o estágio das pesquisas em cada área, procedendo a uma análise sistemática das produções científicas, no intuito de contribuir com novas discussões e reflexões sobre tais pesquisas. Como explica Leite Filho (2008), as pesquisas já realizadas representam um meio de comunicação e indicam o potencial científico de um país. Ressaltam-se, ainda, estudos anteriores, como os de Cella, Rodrigues e Niyama (2011); Avelar et al. (2012); Ribeiro (2013); Cardoso et al. (2005); Mascena, Figueiredo e Boaventura (2013); e Walter et al. (2013), que evidenciam características de pesquisas já realizadas no campo da contabilidade.

Nesse contexto, o presente estudo analisou nas revistas avaliadas pelo Qualis Capes como A1, A2 e B1, no período de 2008 a 2013, artigos que apresentassem no resumo ou nas palavras-chave os termos: "normas internacionais de contabilidade", "IFRS", "pronunciamentos contábeis" e "CPC". A investigação buscou responder ao seguinte problema de pesquisa: quais as discussões permeiam as publicações 
brasileiras em contabilidade relacionadas às normas internacionais ou aos pronunciamentos contábeis nos periódicos nacionais de impacto mais elevado? O objetivo principal consistiu em identificar as principais características das publicações brasileiras em contabilidade dos periódicos com extrato Qualis Capes $\mathrm{A} 1, \mathrm{~A} 2$ e $\mathrm{B} 1$, relacionadas às IFRS e aos CPCs. O estudo justifica-se, assim, por abordar um tema relevante na área da contabilidade, que é a convergência e adoção das IFRS e dos CPCs pelas organizações.

Esta pesquisa está organizada em quatro seções, além desta introdução. A seção 2 aborda os principais aspectos do processo de convergência às normas internacionais de contabilidade, o contexto da regulamentação da contabilidade no Brasil e alguns estudos correlatos à temática estudada; a seção 3 contempla os aspectos metodológicos; a seção 4 consiste na análise e discussão dos resultados; e a seção 5 destina-se às conclusões do estudo.

\section{Referencial teórico}

Nesta seção, abordam-se os aspectos relacionados com a convergência às normas internacionais de contabilidade e alguns estudos anteriores relacionados à temática estudada.

\subsection{Convergência às normas internacionais}

No cenário internacional, em 1973, foi criado o Internacional Accouting Standards Committee (IASC), organismo responsável pelo processo de harmonização da contabilidade. Em 2001, esse órgão passou a ser denominado Internacional Accouting Standards Board (IASB) e recebeu o apoio do G20 (os 20 países mais ricos do mundo) para aprofundar o processo de harmonização internacional. Os objetivos do IASB, conforme Müller e Scherer (2012, p. 30), são "elaborar e publicar, notoriamente, normas con- tábeis internacionais, que deverão ser observadas nos relatórios contábeis e promover a aceitação e adoção prática de tais normas em escala mundial".

Müller e Scherer (2012) destacam o processo observado na elaboração das normas: o tema escolhido é estudado por um grupo de trabalho constituído por representantes dos países membros e assistido pelo secretariado do próprio IASB, a partir do qual é elaborado um projeto de norma para a consideração do conselho; o projeto é estudado em diferentes etapas de desenvolvimento e são formuladas recomendações ao grupo; o texto do projeto é aprovado pelo IASB e enviado a outros organismos com capacidade regulamentadora; durante alguns meses as organizações membros tecem os comentários que são examinados pelo grupo de trabalho e somente após as considerações o conselho aprova de forma definitiva a norma contábil, que deve ser publicada pelas organizações membros em seus respectivos países.

$\mathrm{O}$ IASB emite normas visando à convergência aos padrões contábeis internacionais, com o propósito de atender as necessidades do mercado de capitais, facilitando a elaboração e utilização das demonstrações financeiras. No entanto, a contabilidade, por ser uma ciência social aplicada, é influenciada pelos fatores externos ao ambiente das organizações. Quando cada país adota práticas contábeis diferenciadas, considerando fatores culturais, sociais, econômicos e políticos, fica impossibilitada a compreensão e a comparabilidade dessas práticas em todas as partes do mundo (IUDÍCIBUS et al.; 2013).

No Brasil, a contabilidade sempre sofreu forte influência de organismos governamentais, principalmente no que se refere às legislações tributárias. A Fundação Instituto de Pesquisas Contábeis, Atuariais e Financeiras (FEA/USP) (FIPECAFI, 2008) ressalta "a absoluta necessidade de termos uma única normatização contábil no Brasil, suportada legalmente, mas não limitada 
por esse vínculo, e caminhando rumo a uma única contabilidade mundial". Nesse contexto, Niyama (2010) explicita que, devido à linguagem contábil não ser homogênea e uniforme em termos internacionais, o lucro de empresas brasileiras não será igual ao de empresas de outros países, ainda que sejam adotadas as mesmas práticas de contabilidade, por exemplo.

Padoveze, Benedicto e Leite (2012, p. 9) afirmam que "o fornecimento de informações de acordo com as normas de elevada qualidade, transparência e comparabilidade reduz o risco do investimento e o custo de capital". O mercado de capitais requer normas contábeis em consonância com os padrões internacionais, a fim de que as informações fornecidas aos investidores para a tomada de decisão sejam confiáveis e passíveis de comparação. A esse respeito, sabe-se, por exemplo, que as organizações tendem a possuir vantagens competitivas em relação às demais quando adotam padrões contábeis internacionais.

Tendo em vista a necessidade do mercado de capitais, os profissionais e órgãos de classe da área contábil devem influenciar a promulgação de padrões e critérios direcionados à elaboração de demonstrações contábeis e relatórios de auditoria com maior qualidade, confiabilidade e independência (NIYAMA, 2010). No entanto, Cella, Rodrigues e Niyama (2011) ressaltam que, para fazer frente às mudanças impostas pela convergência à contabilidade internacional e globalização dos relatórios financeiros, o foco dos educadores em contabilidade deve ser a permanente educação continuada de toda a classe contábil, incluindo os educadores, estudantes e profissionais da área.

Devido às alterações advindas do processo de convergência às IFRS, as discussões que permeiam a padronização contábil são crescentes. Hopwood (2007) já indicava as principais áreas promissoras dos estudos em contabilidade, salientando que haveria uma ten- dência de pesquisas voltadas à análise e à forma de padronização das informações contábeis.

\subsection{Estudos correlatos à temática estudada}

A análise bibliométrica é utilizada para identificar as características dos artigos publicados, contribuindo para a identificação de lacunas em pesquisas e da influência que os estudos exercem uns em relação aos outros. A seguir, são abordadas algumas pesquisas bibliométricas que buscam identificar e potencializar as discussões inerentes às características dos estudos em contabilidade.

A pesquisa de Cardoso et al. (2005) analisou a distribuição, as características metodológicas, a evolução e a temática das publicações científicas em contabilidade e a produção de seus autores, no período de 1990 a 2003 nas revistas nacionais classificadas pela $\mathrm{Ca}$ pes com conceito "A". O estudo concluiu que o estado de São Paulo possui o maior número de publicações e que as universidades, em ordem decrescente, que apresentam a maior quantidade de artigos publicados são: Universidade de São Paulo (USP), Fundação Getúlio Vargas - São Paulo (FGV-SP), Fundação Getúlio Vargas - Rio de Janeiro (FGV-RJ) e Universidade Federal do Rio Grande do Sul (UFRGS). Constatou-se também que o número de autores com uma única publicação é maior do que o indicado pela literatura: $80,52 \%$.

Cella, Rodrigues e Niyama (2011) verificaram os temas das pesquisas em educação contábil frente à globalização dos relatórios financeiros e às normas internacionais por meio da análise dos periódicos internacionais. Três temas aparecem com maior frequência: educação continuada da classe contábil; harmonização e convergência internacional da contabilidade; e assuntos para pesquisa em contabilidade.

Ponte et al. (2012) investigaram o grau de cumprimento das orientações definidas pelo CPC 13 pelas empresas 
da BMF\&FBovespa a partir dos Níveis Diferenciados de Governança Corporativa (NDGC). A pesquisa analisou as notas explicativas de uma amostra de 334 empresas, utilizando técnicas de estatística descritiva e testes não paramétricos para aferição das hipóteses. Os resultados gerais do estudo evidenciam o baixo grau de cumprimento das normativas previstas no CPC 13 pelas empresas da amostra, embora tenha sido constatada maior observância em relação ao NDGC.

Avelar et al. (2012) analisaram as características das pesquisas empíricas em contabilidade publicadas nos principais periódicos nacionais da área, no período de 2000 a 2009. Observouse um incremento do número de publicações ao longo do tempo, com uma maior quantidade de artigos na área de contabilidade financeira em comparação às áreas de: contabilidade gerencial e ensino; e pesquisa em contabilidade.

Já o estudo de Ribeiro (2013) explorou a produção acadêmica da Revista de Educação e Pesquisa em Contabilidade, no período de 2007 a 2012, identificando a predominância de artigos elaborados em parceria, isto é, que possuem mais de um autor (cerca de 91\%). A Universidade de São Paulo (USP) destacou-se nas centralidades de grau ( $\mathrm{De}$ gree) e intermediação (Betweenness). Os principais temas da produção do período observado foram: ensino e pesquisa; transparência; contabilidade internacional; e educação contábil.

Walter et al. (2013) verificaram o papel desempenhado pelos autores no desenvolvimento da produção científica brasileira em contabilidade no período de 1994 a 2009. Os pesquisadores foram segregados em cinco grupos: continuantes, transientes, entrantes, one-timers e retirantes. Os resultados demonstraram a importância dos autores continuantes, embora estes representem o menor percentual dentre as categorias possíveis. A maioria dos autores realizou uma única publicação em todo o período analisado.

\section{Método}

A pesquisa classifica-se como descritiva, pois consiste em identificar as características dos artigos publicados nos periódicos com classificação Qualis Capes A1, A2 e B1, no período de 2008 a 2013. É importante ressaltar que, conforme Andrade (2001, p. 124), "neste tipo de pesquisa, os fatos são observados, registrados, analisados, classificados e interpretados, sem que o pesquisador interfira neles".

O critério de inclusão dos artigos analisados foi a presença, no resumo, das palavras "IFRS", "CPC", "pronunciamento contábil" ou "normas internacionais de contabilidade". No que tange aos procedimentos para a coleta dos dados, a pesquisa é considerada de caráter documental, pois consiste em analisar material já elaborado com propósito e público específicos. Com relação à abordagem do problema, o estudo é qualitativo, o que, segundo Raupp e Beuren (2006), proporciona análises mais intensas sobre o elemento em estudo.

A base de dados utilizada para a elaboração da pesquisa é representada por todos os periódicos nacionais publicados entre 2008 e 2013, com qualificação Qualis Capes A1, A2 e B1 no ano de 2013. A justificativa para a escolha de apenas três extratos está na representatividade desses periódicos em relação ao total de revistas. De acordo com a classificação da Capes, esses três extratos somam 658 periódicos, representando $41,51 \%$ do total de 1.585 revistas. Além disso, a análise das características das publicações relacionadas às IFRS e aos pronunciamentos contábeis em apenas três estratos deve complementar as pesquisas realizadas anteriormente por Hopwood e Merchant, autores que ressaltam as dificuldades ou restrições encontradas na realização de estudos com abordagem inovadora.

A pesquisa de Hopwood (2007) identificou restrições na publicação de 
estudos inovadores em contabilidade, especialmente no que tange à aceitação para publicação em revistas especializadas e com maior pontuação de desempenho. As restrições são oriundas da dificuldade encontrada pelos autores de novos estudos de agregarem referências, citações e número de publicações anteriores que permitam atender aos critérios de avaliação, exigidos por estes periódicos, seus avaliadores e editores, além de certa resistência dos avaliadores em aceitarem temas emergentes ou inovadores em contabilidade.

Do mesmo modo, o estudo de Merchant (2010) pondera as dificuldades encontradas por pesquisadores americanos na publicação em outras áreas da contabilidade, além das discussões e linhas de estudo da contabilidade financeira, devido às exigências e aos critérios de avaliação dos Top Journals. $\mathrm{O}$ autor salienta e demonstra em seu estudo as dificuldades que as pesquisas em novas áreas ou relacionadas a temas emergentes encontram para ser aceitas para publicação nas revistas de contabilidade americanas.

Para a consulta dos periódicos, foram utilizados os sites de busca Scientific Periodicals Electronic Library (SPELL) e Scientific Electronic Library Online (SCIELO). No caso dos periódicos que não disponibilizam seus artigos para armazenamento nesses sites de busca, a pesquisa foi realizada diretamente no endereço eletrônico de cada revista.

$\mathrm{O}$ universo da pesquisa é constituído pelas 658 revistas classificadas pela Capes como A1, A2 e B1. Dentre esses, foram escolhidos 43 artigos publicados nas revistas nacionais no período de 2008 a 2013 por apresentarem os termos de interesse deste estudo no resumo. A justificativa para o período selecionado consiste no fato de que o início das publicações dos relatórios financeiros com base nos padrões internacionais de contabilidade ocorre em 2008 no Brasil.

Na Tabela 1, observa-se a composição da amostra de artigos da análise.

Tabela 1 - Revistas com artigos analisados pelo estudo

\begin{tabular}{|c|c|}
\hline Revista & Quantidade de artigos \\
\hline \multicolumn{2}{|c|}{ Revistas com classificação Qualis CAPES A2 } \\
\hline Contabilidade e Finanças - USP & 7 \\
\hline RAE Eletrônica & 1 \\
\hline Revista de Administração Pública & 2 \\
\hline Revista de Administração & 1 \\
\hline Subtotal & 11 \\
\hline \multicolumn{2}{|c|}{ Revistas com classificação Qualis CAPES B1 } \\
\hline $\begin{array}{l}\text { Base - Revista de Administração e } \\
\text { Contabilidade }\end{array}$ & 1 \\
\hline Contabilidade Vista \& Revista & 7 \\
\hline Custose@Gronegócio & 1 \\
\hline $\begin{array}{l}\text { Revista Contemporânea } \\
\text { de Contabilidade }\end{array}$ & 3 \\
\hline $\begin{array}{l}\text { Revista de Contabilidade } \\
\text { e Organizações }\end{array}$ & 8 \\
\hline Universo Contábil & 12 \\
\hline Subtotal & 32 \\
\hline Total & 43 \\
\hline
\end{tabular}

Fonte: Dados da pesquisa 
Observam-se na Tabela 1 as revistas que possuem publicações relacionadas à temática estudada no período de 2008 a 2013, considerando as edições disponíveis na base de dados até a data de 28 de fevereiro de 2014. Pode-se constatar que a Revista Universo Contábil se destaca com maior aceitação de artigos relacionados às novas normas de contabilidade (IFRS e CPC), com 12 artigos, seguida da Revista de Contabilidade e Organizações, com oito publicações, e das revistas Contabilidade e Finanças e Contabilidade Vista \& Revista, cada uma com sete publicações.

Pondera-se como uma das limitações deste estudo a possibilidade de existirem publicações que não apresentam os termos utilizados para seleção no seu resumo, mas que versam sobre a temática. Dessa forma, a análise limitou-se às publicações que utilizaram os termos "normas internacionais de contabilidade", "pronunciamento contábil", "IFRS" e "CPC" em seu resumo.

\section{Apresentação e discussão dos resul- tados}

Esta seção evidencia a formação e análise das redes dos artigos selecionados. São apresentadas características qualitativas e quantitativas da amostra em contribuição às publicações existentes na área.

\subsection{Caracterização da amostra pesquisada}

A Figura 1 apresenta os autores e coautores que aparecem com maior frequência nas 43 publicações selecionadas. Para esta análise, levou-se em consideração a quantidade de autores que contribuíram em cada artigo, bem como o número de vezes que aparecem nos trabalhos estudados.

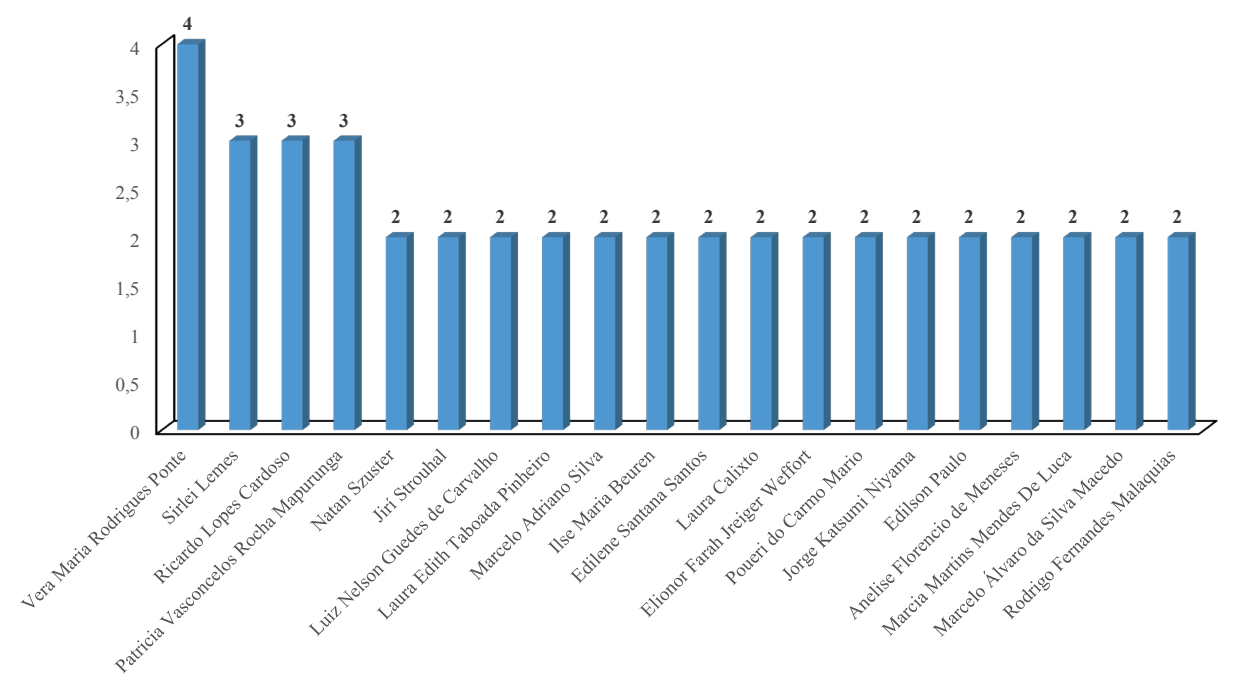

Figura 1 - Autores e coautores que aparecem com maior frequência nas publicações Fonte: dados da pesquisa

Com base na Figura 1, percebe-se a presença da autora Vera Maria Rodrigues Ponte em quatro artigos publicados. Em seguida, aparecem os pesquisadores Sirlei Lemes, Ricardo Lopes Cardoso e Patrícia Vasconcelos Rocha Mapurunga, com participação em três publicações cada. Outros 16 autores constam em duas publicações e 76 autores aparecem em apenas uma publicação.

Os autores que aparecem em apenas uma publicação representam 79,2\% da amostra, e os pesquisadores que publicaram dois ou mais estudos equivalem 
a $20,8 \%$. Esse resultado é similar ao da pesquisa de Ribeiro (2013), que encontrou o percentual de $15,3 \%$ para autores com mais de uma publicação dentre as analisadas. Em média, no período estu- dado, cada artigo recebeu a colaboração de 2,81 autores, resultado semelhante ao encontrado por Ribeiro (2013), o qual identificou uma média de 3,08 pesquisadores por publicação em 2012.

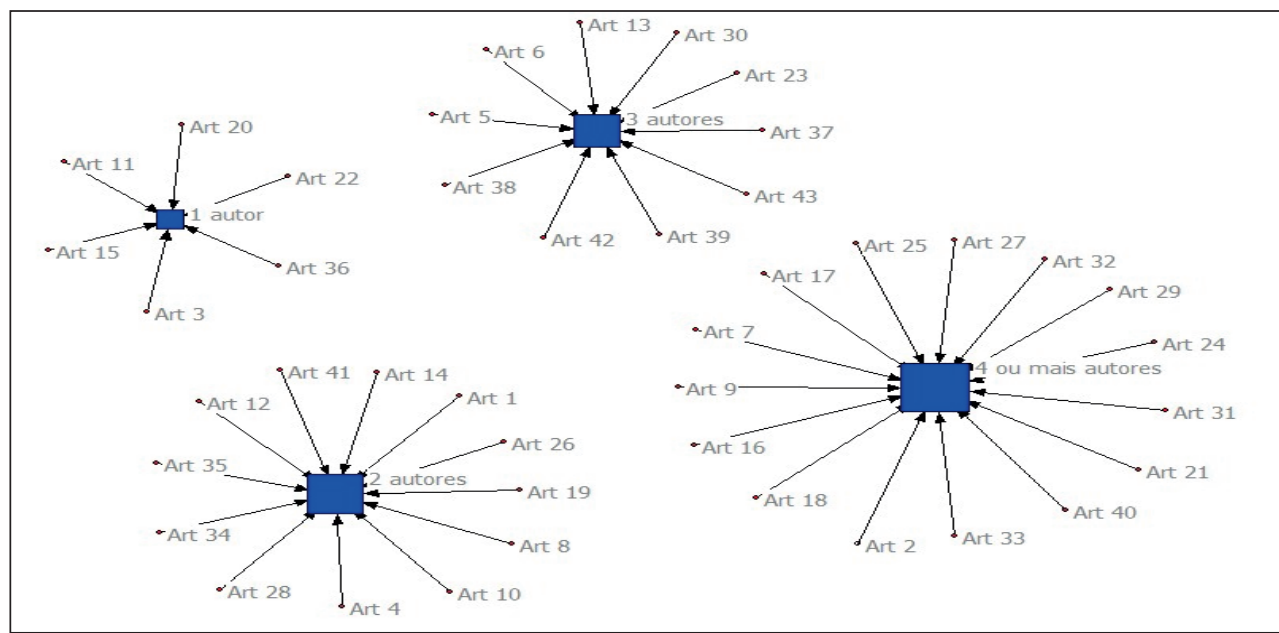

Figura 2 - Rede de autores por publicação

Fonte: dados da pesquisa

A Figura 2 evidencia que a maioria dos artigos (15) tem quatro ou mais autores, representando $34,9 \%$ dos artigos. Em seguida, aparecem 12 publicações com dois autores, equivalente a $27,9 \%$ do total. As pesquisas com três autores somam 10 artigos e representam 23,3\% das publicações. Com menor centralidade na rede, constam os artigos com apenas um autor, totalizando seis artigos ou
$14 \%$ da amostra. Observa-se, assim, que em $86 \%$ dos artigos pesquisados existe a contribuição de mais de um autor.

Discussões de estudos anteriores indicam o cenário científico ideal quando existir a formação de redes entre os autores, inibindo a redundância de publicações. Nesse sentido, há a Figura 3, que demonstra a rede das publicações por período analisado.

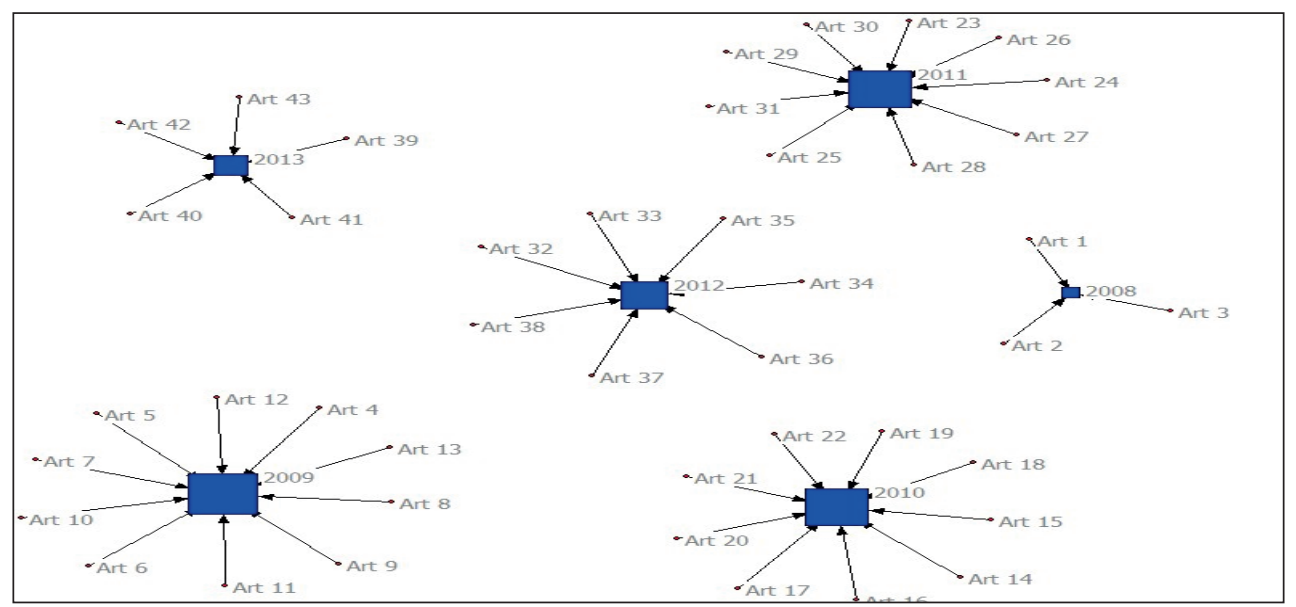

Figura 3 - Rede de publicação por período Fonte: dados da pesquisa 
A rede dos artigos publicados em cada ano evidencia maior centralização no período de 2009 , com 10 publicações, representando $23,3 \%$ da amostra. Em 2010 e 2011, foram publicados nove artigos, equivalente a 20,9\%. Apesar das alterações contínuas emitidas pelo CPC, por meio de pronunciamentos contábeis, orientações e interpretações técnicas, nos períodos de 2012 e 2013 , houve redução na quantidade de artigos publicados, conforme demonstra a Fi- gura 3. Foram identificados sete artigos em 2012 e cinco em 2013. O período inicial de adoção das normas internacionais (2008) também consta na rede com três pesquisas, representando $7 \%$ do total, justificado pela recente mudança e possivelmente pelas dificuldades iniciais de interpretação.

A Tabela 2 apresenta as temáticas com maior predominância dentre os artigos analisados, com base no resumo e nos objetivos da pesquisa.

Tabela 2 - Assuntos abordados por período

\begin{tabular}{|c|c|c|c|c|c|c|c|c|}
\hline Assunto & 2008 & 2009 & 2010 & 2011 & 2012 & 2013 & Total & $\%$ \\
\hline $\begin{array}{l}\text { Efeitos e impactos da adoção } \\
\text { dos padrões IFRS }\end{array}$ & 3 & 6 & 3 & 6 & 6 & 2 & 26 & 60,47 \\
\hline $\begin{array}{l}\text { Métodos de ensino-apren- } \\
\text { dizagem da contabilidade e } \\
\text { demanda de profissionais ca- } \\
\text { pacitados face às IFRS }\end{array}$ & & 1 & 1 & 2 & & & 4 & 9,30 \\
\hline $\begin{array}{l}\text { Percepção dos profissionais } \\
\text { e estudantes quanto à adoção } \\
\text { dos padrões internacionais }\end{array}$ & & & 1 & & 1 & 1 & 3 & 6,98 \\
\hline $\begin{array}{l}\text { Evidenciação das informa- } \\
\text { ções divulgadas pelas entida- } \\
\text { des públicas }\end{array}$ & & 1 & 1 & & & & 2 & 4,65 \\
\hline $\begin{array}{l}\text { Comparabilidade da relevân- } \\
\text { cia da DOAR e DFC na to- } \\
\text { mada de decisão }\end{array}$ & & 1 & & & & & 1 & 2,33 \\
\hline $\begin{array}{l}\text { Normatização contábil ba- } \\
\text { seada em princípios ou re- } \\
\text { gras }\end{array}$ & & & 1 & & & & 1 & 2,33 \\
\hline $\begin{array}{l}\text { Comparativo entre as IFRS } \\
\text { e as normas contábeis atuais } \\
\text { da Macedônia e Albânia }\end{array}$ & & & 1 & & & & 1 & 2,33 \\
\hline $\begin{array}{l}\text { Regulamentação contábil à } \\
\text { luz da teoria tridimensional }\end{array}$ & & & 1 & & & & 1 & 2,33 \\
\hline $\begin{array}{l}\text { Aceitação das normas inter- } \\
\text { nacionais pelas pequenas e } \\
\text { médias empresas }\end{array}$ & & & & 1 & & & 1 & 2,33 \\
\hline Governança corporativa & & & & & & 1 & 1 & 2,33 \\
\hline Risco de mercado & & & & & & 1 & 1 & 2,33 \\
\hline $\begin{array}{l}\text { Comparabilidade entre os } \\
\text { resultados em BR GAAP e } \\
\text { U.S. GAAP }\end{array}$ & & 1 & & & & & 1 & 2,33 \\
\hline $\begin{array}{c}\text { TOTAL } \\
\end{array}$ & 3 & 10 & 9 & 9 & 7 & 5 & 43 & 100 \\
\hline
\end{tabular}

Fonte: dados da pesquisa 
Artigos sobre os "Efeitos e impactos da adoção dos padrões IFRS" representaram $60,47 \%$ dos assuntos abordados pelas pesquisas no período analisado. Já a temática "Métodos de ensino-aprendizagem da contabilidade e demanda de profissionais capacitados frente às IFRS" foi abordada em quatro estudos ou $9,33 \%$ das pesquisas, seguida de três pesquisas que discutiram a "Percepção dos profissionais e estudantes com a adoção dos padrões internacionais" e de duas referentes à "Evidenciação das informações divulgadas pelas entidades públicas". Outros oito estudos abordavam temáticas diferentes relacionadas às normas internacionais de contabilidade, conforme a Tabela 2 .

Com relação às discussões das pesquisas abordando os "Efeitos e impactos da adoção dos padrões IFRS", observou-se que os artigos analisam a aplicação de um CPC, uma IFRS ou uma IAS específica, ou a adoção dos padrões internacionais de contabilidade, observando os efeitos e impactos provocados pela Lei 11.638/2007. A maioria desses artigos pesquisou um grupo de empresas de determinado setor, público ou privado; quatro artigos realizaram pesquisas bibliográficas e duas publicações aprofundaram as pesquisas, realizando estudos de caso. Esse assunto foi analisado também por seis publicações que versavam sobrea empresas estrangeiras.

$\mathrm{O}$ assunto "Métodos de ensino-aprendizagem da contabilidade e demanda dos profissionais capacitados face às IFRS" representa 9,3\% dos estudos, os quais tiveram como objetivo identificar: a demanda por profissionais com conhecimento em IFRS na cidade de São Paulo; as publicações em rela- ção à educação contábil frente às IFRS e os conhecimentos, as habilidades e os métodos de instrução utilizados para o alcance do aprendizado.

No que se refere à percepção dos profissionais e estudantes quanto à adoção dos padrões internacionais, foram levantadas as expressões de incertezas contidas nos pronunciamentos técnicos contábeis. Especificamente, questionaram-se os profissionais e/ou estudantes sobre os impactos da adoção das IFRS em empresas de saneamento básico e as informações contidas no CPC 25.

Os demais assuntos evidenciados na Tabela 2, de certa forma, relacionamse com as palavras-chave "normas internacionais de contabilidade", "CPC" e "IFRS". Com apenas uma publicação dentre os artigos analisados, estão os assuntos: comparabilidade da relevância da DOAR e DFC na tomada de decisão; normatização contábil baseada em princípios ou regras; comparativo entre as IFRS e as normas contábeis atuais da Macedônia e Albânia; regulamentação contábil à luz da teoria tridimensional; aceitação das normas internacionais pelas pequenas e médias empresas; governança coorporativa; risco de mercado; e comparabilidade entre os resultados em BR GAAP e U.S. GAAP.

No que tange às dificuldades encontradas para a comparabilidade das informações apresentadas em padrões diferenciados e do risco de mercado, estes devem ser minimizados com a adoção dos padrões internacionais de contabilidade IFRS.

Analisando-se a metodologia utilizada pelos autores na elaboração dos artigos pesquisados, a Figura 4 apresenta a rede de classificação da pesquisa quanto aos objetivos. 


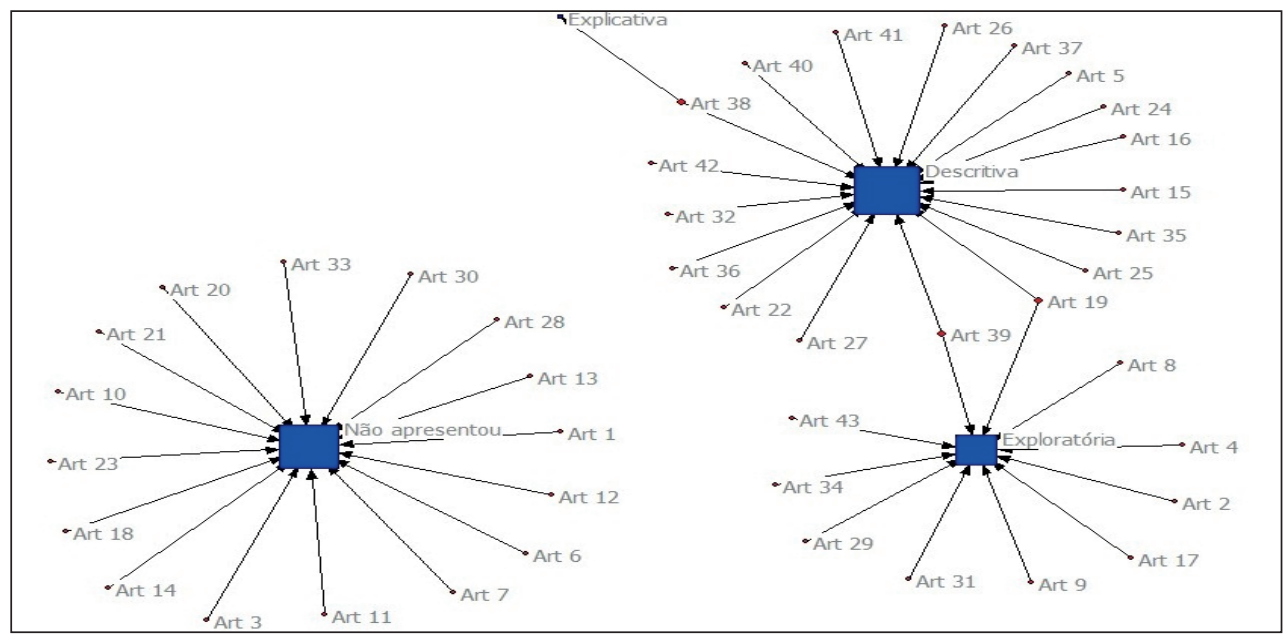

Figura 4 - Rede de classificação metodológica quanto aos objetivos

Fonte: dados da pesquisa

Verifica-se, como demonstra a Figura 4, que há maior centralização dos estudos classificados quanto aos objetivos como pesquisa descritiva (18 artigos). Existe interação entre alguns artigos classificados como pesquisa descritiva e exploratória. Uma pesquisa foi identificada pelo autor como explicativa e ao mesmo tempo descritiva. As pesquisas exploratórias totalizaram 11 publicações.

Aparecem de forma isolada na rede 16 pesquisas, em que não foi pos- sível identificar a classificação metodológica quanto aos objetivos, já que os autores não realizaram esse tipo de especificação. Os achados coincidem com a pesquisa de Ribeiro (2013), Cardoso et al. (2005), Carneiro et al. (2012) e Mascena, Figueiredo e Boaventura (2013), no que tange à predominância de estudos com característica descritiva.

A Figura 5 evidencia em rede a classificação das pesquisas quanto aos procedimentos metodológicos adotados para a análise dos resultados.

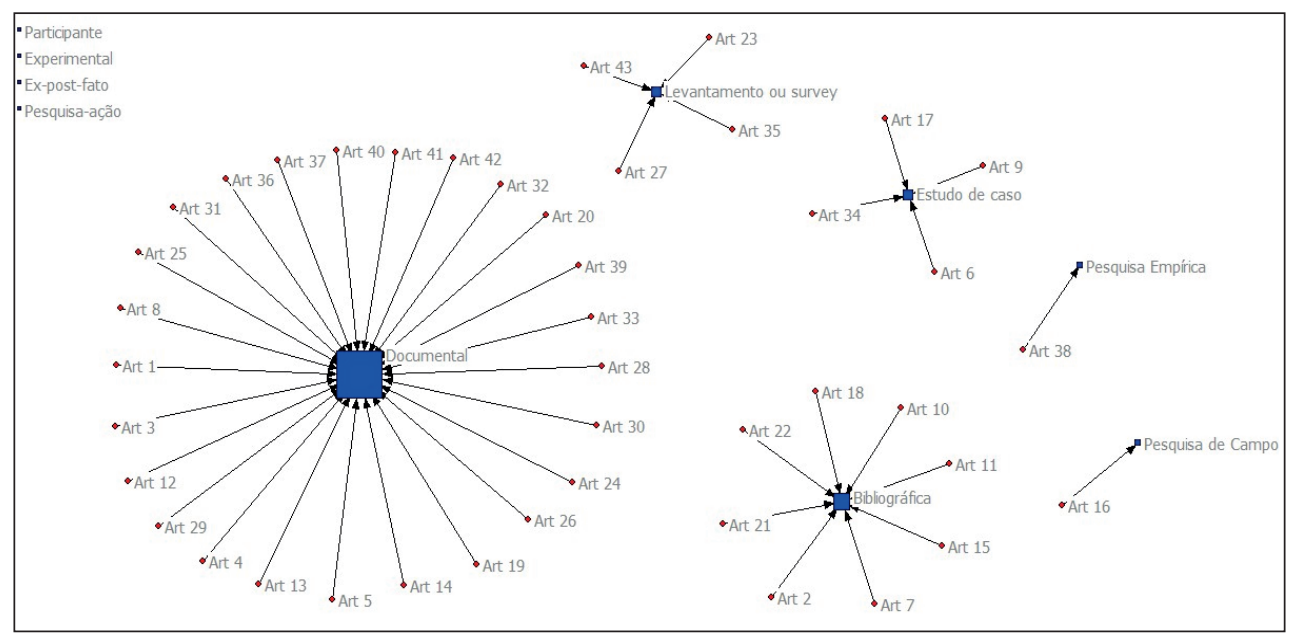

Figura 5 - Procedimentos metodológicos

Fonte: dados da pesquisa 
A Figura 5 apresenta os procedimentos utilizados pelos pesquisadores para a coleta de dados. A pesquisa documental representou a maioria $(58,1 \%)$ dos artigos analisados, seguida da pesquisa bibliográfica, com 18,6\% dos artigos. As técnicas de estudo de caso e de levantamento ou survey foram utilizadas, cada qual, em 9,3\% dos artigos da amostra. Já a pesquisa empírica e a pesquisa de campo aparecem uma única vez.

Dando sequência a análise dos procedimentos metodológicos, a Figura 6 demonstra a classificação da pesquisa quanto à abordagem do problema.

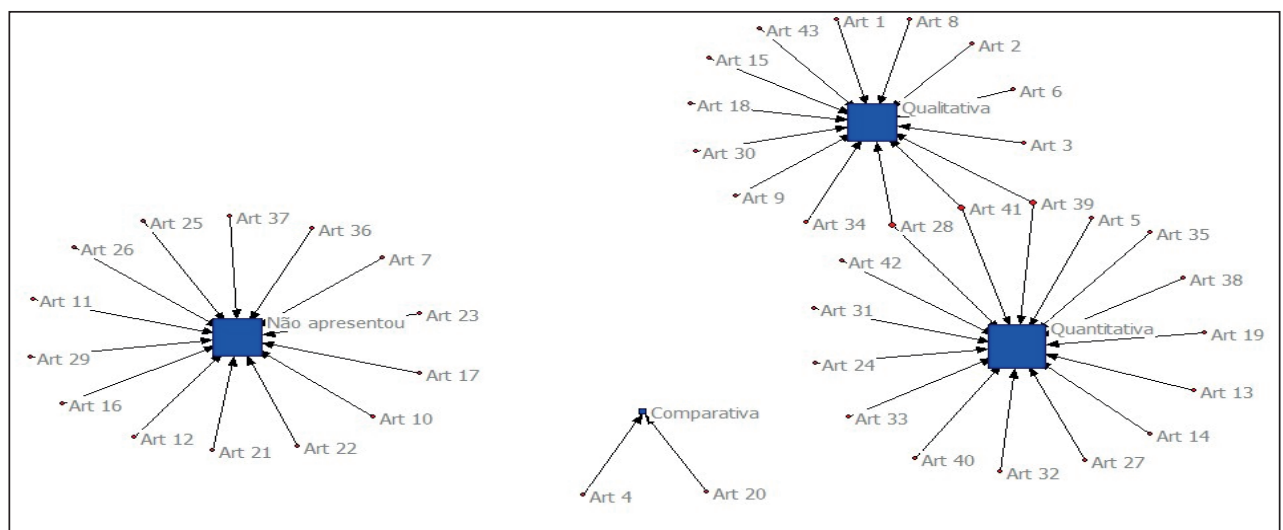

Figura 6 - Rede de classificação metodológica quanto ao problema

Fonte: dados da pesquisa

Constata-se pela Figura 6 que os artigos 28 e 39, relacionados ao assunto "Efeitos e impactos da adoção dos padrões IFRS", e o artigo 41, com o tema "Risco de mercado", utilizaram a pesquisa qualitativa e quantitativa. Ao todo, 14 pesquisas se classificam como tendo abordagem qualitativa e outras 16 se apresentam como sendo de abordagem quantitativa. Foram encontrados dois artigos intitulados, quanto ao problema, como pesquisa comparativa. No entanto, alguns autores não classificaram sua pesquisa em relação a esse aspecto, constando na rede como "não apresentou".

A Figura 7 evidencia os métodos de pesquisa utilizados pelos autores.

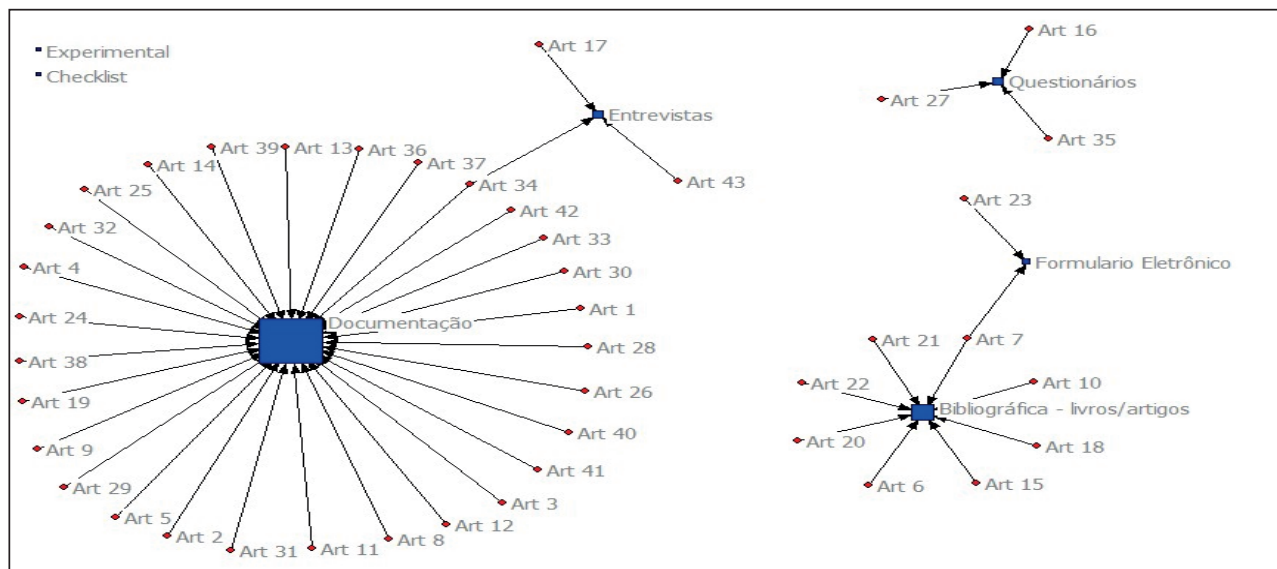

Figura 7 - Rede técnicas de coleta dos dados

Fonte: dados da pesquisa 
Analisando-se a Figura 7, verifica-se a predominância das pesquisas documentais, técnica utilizada em $64,4 \%$ dos artigos estudados. As pesquisas bibliográficas aparecem em seguida, representando $17,8 \%$ dos estudos. Observou-se em alguns artigos a presença de duas técnicas de coleta de dados, ocorrendo interação entre a pesquisa documental com entrevistas e a pesquisa bibliográfica com utilização de formulários eletrônicos.

As pesquisas realizadas diretamente com os profissionais das empresas estudadas são menos frequentes: aparecem em apenas três artigos que se utilizam de questionários e em outros três que citam a entrevista como forma de coleta de informações.

Esta investigação também identificou nos artigos pesquisados a metodologia utilizada para a análise dos dados, evidenciadas por meio de rede na Figura 8.

No que tange às técnicas de análise dos dados, a Figura 8 evidencia a utilização da análise de conteúdo e da análise descritiva, com $27,3 \%$ e $22,7 \%$ dos estudos, respectivamente. A análise documental e de correlação também estão entre as mais utilizadas, com nove e 10 publicações, respectivamente. A análise multivariada aparece em apenas quatro estudos ( $9,1 \%$ dos artigos).

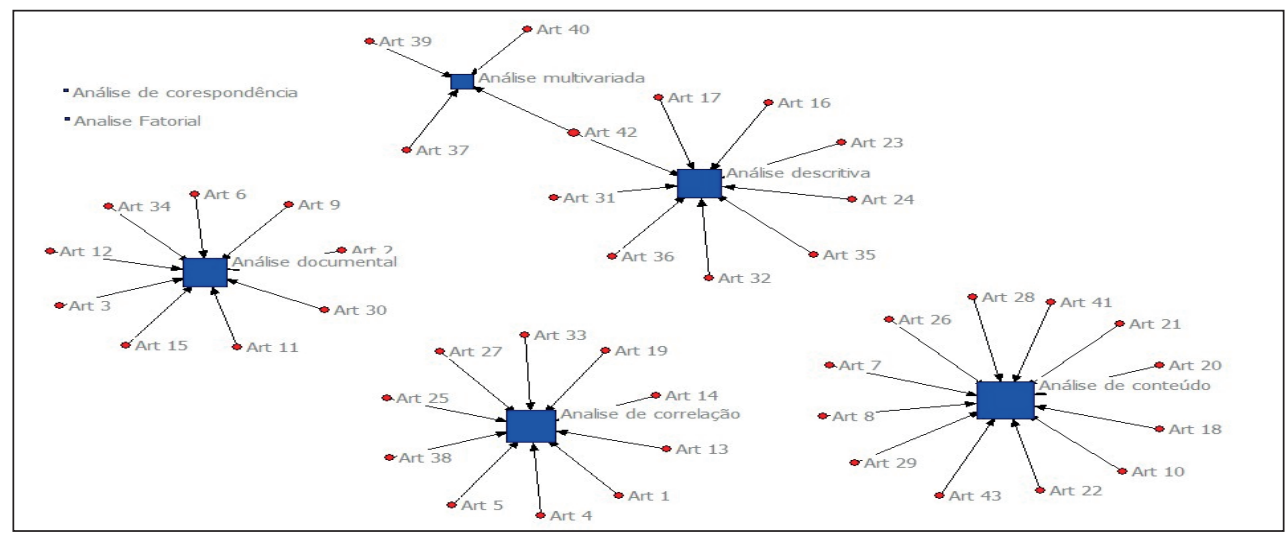

Figura 8 - Rede técnicas de análise dos dados

Fonte: dados da pesquisa

Este estudo buscou identificar, pelos autores, conforme demonstrado também, qual foi o universo pesquisado na rede da Figura 9.

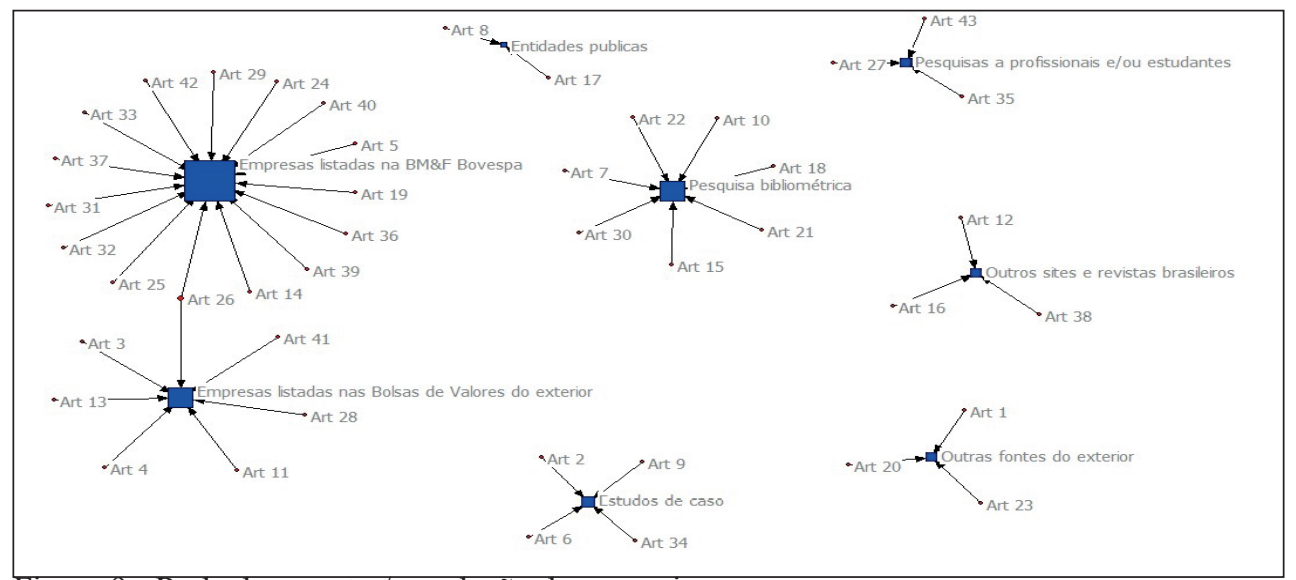

Figura 9 - Rede da amostra/população das pesquisas

Fonte: dados da pesquisa 
A Figura 9 evidencia a centralização da amostra ou população das pesquisas nas empresas listadas na BM\&FBovespa. Dos 43 artigos, 15 dizem respeito a empresas obrigadas a publicar as demonstrações contábeis, por estarem listadas na Bolsa de Valores. São exemplos do universo de pesquisa dos autores os estudos de caso realizados na Eternit, Gol, Lupatech, Renar e São Carlos, além das empresas listadas nos níveis diferenciados de governança corporativa, todas as companhias não financeiras, empresas do setor elétrico ou que continham características específicas, como a apresentação dos ativos biológicos.

Na sequência, identificou-se a realização de pesquisas bibliométricas e de pesquisas referentes a empresas listadas nas Bolsas de Valores do exterior, cada uma com sete artigos. Quanto às Bolsas de Valores do exterior, as pesquisas foram realizadas nas empresas listadas na Bolsa de Valores de Praga, na Bolsa de Valores de nova Iorque (NYSE), na Associação Nacional de Corretores de Títulos de Cotações Automáticas (NASDAQ), no Mercado de ações oficial de Portugal, na Bolsa de Valores de Madrid e Londres e na Euronext Lisboa.

$\mathrm{Na}$ rede, quatro artigos foram identificados como estudo de caso. As empresas pesquisadas foram a Petrobrás, a Companhia Vale do Rio Doce, a Gerdau S.A e uma sociedade de capital aberto do ramo têxtil, não indicada diretamente.

Os três estudos que buscaram informações nos outros sites e nas revistas brasileiros, consultaram Catho, Michael Page Internacional, endereço eletrônico das próprias empresas classificadas no ranking "Valor 1000: 1000 maiores empresas" de agosto de 2007 do Valor Econômico e listadas na base de dados "Séries Econômico-Financeiros do setor elétrico do GESEL/UFRJ".

$\mathrm{Na}$ rede de pesquisa relacionada aos profissionais e estudantes, foram questionados/entrevistados estudantes matriculados em cursos de graduação de várias Instituições de Ensino Supe- rior (IES) brasileiras, discentes do curso de graduação de ciências contábeis da Universidade Federal de Uberlândia, profissionais contábeis, auditores, advogados e tributaristas. Os dois artigos que analisaram informações de entidades públicas pesquisaram os quatro governos estaduais da região sudeste do Brasil e o estado de Minas Gerais em específico.

\subsection{Análise dos resultados}

De forma geral, os achados contribuem para as pesquisas de Avelar et al. (2012), Ribeiro (2013), Cardoso et al. (2005), Mascena, Figueiredo e Boaventura (2013) e Carneiro et al. (2012), as quais apresentaram resultados condizentes com os deste estudo. A predominância de artigos em parceria, por exemplo, representa $90,57 \%$ na pesquisa de Ribeiro (2013) e $65 \%$ no estudo de Avelar et al. (2012). Já autores com apenas uma publicação, conforme pesquisa de Ribeiro (2013), somam 84,77\% dos casos e, de acordo com Avelar et al. (2012), 81,9\%. Por meio desses índices, é possível concluir que a maioria dos autores não é continuante, prejudicando o nível das informações publicadas e a sequência das discussões acerca dos temas pesquisados.

No que tange à metodologia utilizada para a elaboração dos artigos, constatou-se resultados semelhantes aos de Avelar et al. (2012), que indicam predominância da abordagem quantitativa em $50,12 \%$ das pesquisas. Dentre as técnicas de coleta de dados mais utilizadas, aparece a pesquisa documental com 33,18\% no estudo de Avelar (2012) e $34 \%$ no estudo de Mascena, Figueiredo e Boaventura (2013), que identificou o mesmo percentual para o método das entrevistas. Para o tratamento dos dados, sobressaiu-se, com base na pesquisa de Cardoso et al. (2005), a análise descritiva, representando $41,7 \%$. No entanto, o estudo de Mascena, Figueiredo e Boaventura (2013) apresentou a dominação da análise exploratória $(71 \%)$, seguida 
da descritiva (29\%). As características metodológicas das pesquisas indicam atenção especial ao aspecto quantitativo, o que restringe a análise do ponto de vista das pessoas e da relação com o objeto pesquisado. Além disso, há pouca utilização da pesquisa exploratória, a qual visa ao debate de assuntos com poucas publicações anteriores. A pesquisa documental é utilizada com maior frequência, devido à dificuldade encontrada pelos pesquisadores para coletar dados por meio de entrevistas, questionários ou formulários.

Quanto às características das publicações brasileiras em contabilidade nos periódicos com extrato Qualis Capes $\mathrm{A} 1, \mathrm{~A} 2 \mathrm{e} \mathrm{B} 1$, relacionadas às IFRS e aos CPCs, constatou-se no período analisado (justificado pelo início da adoção dos padrões internacionais - 2008 a 2013) que o maior número de publicações ocorreu no ano de 2009 (23,3\% da amostra), seguido por 2010 e 2011, com 20,9\% cada.

Identificou-se, quanto à rede dos autores das publicações, que $79,2 \%$ dos autores possuem apenas uma publicação Dentre aqueles que possuem dois ou mais artigos constam Vera Maria Rodrigues Ponte, Sirlei Lemes, Ricardo Lopes Cardoso e Patricia Vasconcelos Rocha Mapurunga. Observou-se a predominância da publicação de artigos em parceria, pois apenas $14 \%$ da amostra apresenta um autor. Percebeu-se, também, maior centralidade de grau e de intermediação para os artigos com quatro ou mais autores $(34,9 \%)$, evidenciando que ainda não há destaque para novos formadores de opinião ou pesquisadores, mas uma diversidade de pesquisadores investigando sobre a temática. Diante desse quadro, ressaltam-se os benefícios da publicação em parceria, devido à troca de informações entre os autores, além da inibição da redundância de publicações relacionadas ao mesmo tema.

Observou-se, ainda, a centralização de grau e intermediação para realização das pesquisas em empresas listadas na BM\&F Bovespa (34,88\%), o que indica que a amostra/população estudada pelos autores consiste principalmente nas empresas listadas na Bolsa de Valores. Essa variável é importante aos estudos, pois evidencia que grande parte dos pesquisadores opta por analisar empresas que publicam as Demonstrações Financeiras pela facilidade de coleta dos dados.

\section{Considerações finais}

Este estudo analisou as publicações no período de 2008 a 2013 das revistas qualificadas pela Capes como A1, $\mathrm{A} 2$ e B1, que continham os termos "normas internacionais de contabilidade", "pronunciamento contábil", "IFRS" e "CPC" no resumo. Identificaram-se 43 artigos com essas características, os quais foram analisados quanto às redes de autoria, ao ano de publicação, aos aspectos metodológicos, ao assunto e ao universo de pesquisa, fim de averiguar as discussões que permeiam as publicações brasileiras em contabilidade relacionadas às normas internacionais ou aos pronunciamentos contábeis, nos periódicos nacionais de impacto mais elevado.

Os resultados indicam que $o$ tema dos "Efeitos e impactos dos padrões IFRS" foi estudado por $60,47 \%$ da amostra, evidenciando a preocupação dos autores em verificar a publicação das demonstrações financeiras por parte das empresas, de acordo com as normas internacionais e as alterações provocadas na elaboração, mensuração e evidenciação das IFRS e CPCs. $\mathrm{Na}$ sequência, com 9,3\%, aparece outro assunto de grande importância para o setor contábil: "Métodos de ensino -aprendizagem da contabilidade e demanda de profissionais capacitados face ao IFRS", referindo-se às mudanças nas instituições de ensino com vistas à capacitação dos profissionais e docentes, além do interesse das empresas por pessoas com conhecimento sobre essa normatização. 
Os resultados evidenciam, ainda, a predominância de pesquisas de cunho documental a partir da análise das notas explicativas, relacionando o contexto das normas e as práticas empresariais, tanto no sentido de verificar a adoção quanto no sentido de observar as mudanças ou os impactos da adoção das IFRS ou CPCs para as empresas.

Pode-se concluir que os periódicos brasileiros necessitam de publicações com análise mais aprofundada desses assuntos, valorizando a informação qualitativa, a aplicação dos conceitos já existentes para a resolução de novos problemas ou a identificação de novas teorias, baseados na problemática proposta. Além disso, é fundamental a ampliação da rede de amostra e população pesquisada, a fim de evidenciar as Demonstrações Financeiras e práticas contábeis utilizadas pelas empresas de pequeno e médio porte, considerando que essas representam mais de $80 \%$ das empresas e possuem grande importância na economia do país.

Salienta-se, também, a limitação na quantidade de estudos e pesquisas relacionadas às normas internacionais publicadas nos periódicos analisados no período de 2008-2013, especialmente diante do contexto brasileiro, que trouxe tantas alterações (mais de 40 CPCs) a serem realizadas em um curto período de tempo. Chama atenção a evolução da quantidade de estudos publicados, em 2008, de acordo com pesquisa realizada pela Thomson Reuters, foram aprovados por periódicos brasileiros 30.021 artigos; em 2011, conforme estudo do Jornal Folha de São Paulo na base de dados Scimago, esse número passou para 49.664. Apesar disso, considerando a quantidade de artigos publicados nos extratos $\mathrm{A} 1, \mathrm{~A} 2$ e $\mathrm{B} 1$, conforme os critérios de seleção adotados por este estudo, percebe-se que apenas 43 estudos abordaram assuntos relacionados aos padrões internacionais de contabilidade, discutidos no Brasil a partir de 2008. Esses resultados complementam as pesquisas de Hop- wood (2010) e Merchant (2007) no que se refere à resistência dos avaliadores em aceitarem temas emergentes ou inovadores em contabilidade.

Esse contexto motiva a realização de novas pesquisas voltadas ao processo de implantação dos pronunciamentos contábeis vigentes. No intuito de promover as discussões sobre as publicações relacionadas à convergência e adoção das normas internacionais de contabilidade, ressalta-se a necessidade de uma continuidade na elaboração desse tipo de pesquisa. Dessa forma, será possível identificar os avanços técnicos e interpretativos nas informações contábeis fornecidas aos usuários.

\section{Referências}

1. ANDRADE, M. M. Introdução à metodologia do trabalho científico: elaboração de trabalhos na graduação. 5. ed. São Paulo: Atlas, 2001.

2. AVELAR, E. A.; SANTOS, T. S.; RIBEIRO, L. M. P.; OLIVEIRA, C. C. Pesquisa em contabilidade: uma análise dos estudos empíricos publicados em periódicos nacionais entre 2000 e 2009. Revista Universo Contábil, v. 8, n. 3, p. 06-23, 2012.

3. CARDOSO, R. L; NETO, O. R. M.; RICCIO, E. L.; SAKATA, M. C. G. Pesquisa científica em contabilidade entre 1990 e 2003. Revista de Administração de Empresas, v. 45, n. 2, 2005.

4. CARNEIRO, A. F.; NETO, J. M. S.; LOCKS, R.; SANTOS, M. M. A. Custos na administração pública: revisão focada na publicação de artigos científicos a partir da promulgação da Lei de Responsabilidade Fiscal. Revista Contemporânea de Contabilidade, v. 9, n. 18, p. 03-22, 2012.

5. CARVALHO, N. L.; LEMES, S.; COSTA, F. M. Contabilidade internacional: aplicação das IFRS 2005. São 
Paulo: Atlas, 2006.

6. CELLA, G.; RODRIGUES, J. M.; NIYAMA, J. K. Contabilidade internacional - análise dos periódicos internacionais sobre pesquisas em educação contábil face à convergência e globalização. Revista Contemporânea de Contabilidade, v. 8, n, 15, p. 177-198, 2011.

7. CONSELHO FEDERAL DE CONTABILIDADE. Resolução CFC $\mathbf{n}^{\mathbf{0}}$ 1.055/05: cria a Comitê de Pronunciamentos Contábeis - CPC, e dá outras providências. Disponível em: http:// www2.cfc.org.br/sisweb/sre/detalhes sre.aspx?Codigo $=2005 / 001055$. Acesso: 26 fev. 2014.

8. ERNST \& YOUNG; FIPECAFI. Manual de normas internacionais de contabilidade: IFRS versus normas brasileiras, v. 2. São Paulo: Atlas, 2010.

9. FIPECAFI - FUNDACÃO INSTITUTO DE PESQUISAS CONTÁBEIS, ATUARIAIS E FINANCEIRAS. Manual de contabilidade das sociedades por ações: aplicável às demais sociedades. 7. ed. São Paulo: Atlas, 2008.

10. HOPWOOD, A. G.; Whither accounting research? The Accounting Review, v. 82, n. 5, p. 1365 -1374, 2007.

11. JORNAL FOLHA DE SÃO PAULO. Produção científica do Brasil aumenta, mas qualidade cai. Disponível em: http://www1.folha.uol.com.br/fsp/ cienciasaude/105099-producao-cientifica-do-brasil-aumenta-mas-qualidadecai.shtml. Acesso em: 11/06/2014.

12. LEITE FILHO, G. A. Padrões de produtividade de autores em periódicos e congressos na área de contabilidade no Brasil: um estudo bibliométrico. Revista de Administração Contemporânea, v. 12, n. 2, p. 533-554, 2008

13. MACEDO, M. A. S.; CASA NOVA, S. P. C.; ALMEIDA, K. Mapeamento e análise bibliométrica da utilização da Análise Envoltória de Dados - DEA em estudos em contabilidade e Administra- ção. Contabilidade, Gestão e Governança, v. 12, n. 3, p. 87-101, 2009.

14. MASCENA, K. M. C.; FIGUEIREDO, F. C.; BOAVENTURA, J. M. G. Clusters e APL's: análise bibliométrica das publicações nacionais no período de 2000 a 2011. Revista de Administração de Empresas, v. 53, n. 5, p. 454468, 2013.

15. MERCHANT, KENNETH A. Paradigms in accounting research: A view from North America. Management Accounting Research, v. 21, n. 2, p. 116120, 2010.

16. IUDÍCIBUS, S. de; MARTINS, E.; GELBECKE, E. R.; FUNDAÇÃO INSTITUTO DE PESQUISAS CONTÁBEIS, ATUARIAIS E FINANCEIRAS. Manual de contabilidade societária: aplicável a todas as sociedades. 2. ed. São Paulo: Atlas, 2013.

17. MÜLLER, A. N.; SCHERER, L. M. Contabilidade avançada e internacional. 3. ed. São Paulo: Saraiva, 2012.

18. NIYAMA, J. K. Contabilidade internacional. 2. ed. São Paulo: Atlas, 2010 .

19. PADOVEZE, C. L.; BENEDICTO, G. C.; LEITE, J. S. J. Manual de contabilidade internacional: IFRS, US GAAP e BR GAAP: Teoria e prática. São Paulo: Cengage Learning, 2012.

20. PONTE, V. M. R. ; DE LUCA, M. M. M. ; OLIVEIRA, Marcelle Colares ; AQUINO, L. D. P. ; CAVALCANTE, D. S. . Análise do grau de cumprimento das práticas de divulgação definidas pelo Pronunciamento Técnico CPC 13 no âmbito das companhias abertas. Revista de Educação e Pesquisa em Contabilidade, v. 6, p. 38-53, 2012.

21. RAUPP, M.; BEUREN, I. M. Metodologia da pesquisa aplicável às ciências sociais. In: BEUREN, I. M (Org). Como elaborar trabalhos monográficos em contabilidade: teoria e prática. 3 ed. São Paulo: Atlas, 2006. 
22. RIBEIRO, H. C. M. Características da produção veiculada na revista de educação e pesquisa em contabilidade no período de 2007 a 2012. Revista de Educação e Pesquisa em Contabilidade, v. 7, p. 424-443, 2013.

23. WALTER, S. A.; BACH, T. M.; DOMINGUES, M. J. C.S.; FREGA, J. R. Permanência e inserção de atores na produção científica de 1994 a 2009 na área de contabilidade. Revista de educação e pesquisa em contabilidade, $v$. 7, n. 2, p. 199-214, 2013. 